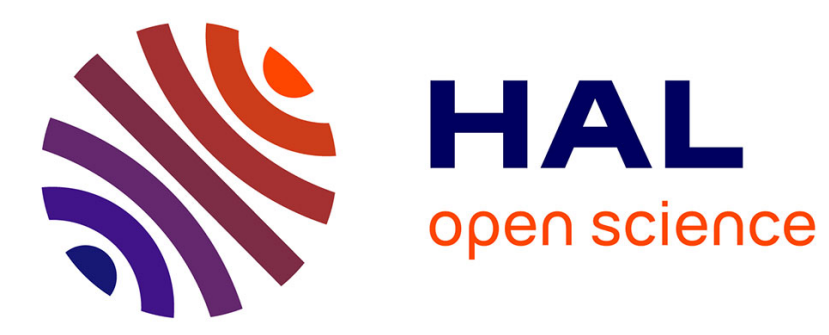

\title{
Non linear recombination processes: application to quantitative implantation characterization
}

B. Forget, D. Fournier, Vitali Goussev

\section{To cite this version:}

B. Forget, D. Fournier, Vitali Goussev. Non linear recombination processes : application to quantitative implantation characterization. Journal de Physique IV Proceedings, 1994, 04 (C7), pp.C7-155C7-158. 10.1051/jp4:1994737 . jpa-00253266

\section{HAL Id: jpa-00253266 https://hal.science/jpa-00253266}

Submitted on 1 Jan 1994

HAL is a multi-disciplinary open access archive for the deposit and dissemination of scientific research documents, whether they are published or not. The documents may come from teaching and research institutions in France or abroad, or from public or private research centers.
L'archive ouverte pluridisciplinaire HAL, est destinée au dépôt et à la diffusion de documents scientifiques de niveau recherche, publiés ou non, émanant des établissements d'enseignement et de recherche français ou étrangers, des laboratoires publics ou privés. 


\title{
Non linear recombination processes: application to quantitative implantation characterization
}

\author{
B.C. Forget, D. Fournier and V.E. Gusev \\ Laboratoire d'Instrumentation, Université Pierre et Marie Curie, ESPCI, 10 rue Vauquelin, 75005 Paris, \\ France \\ * International Laser Center, Moscow State University, 119899 Moscow, Russia
}

\begin{abstract}
Previous photoreflectance studies on intrinsic silicon have exposed the strong non linearities versus excitation power. Implanted silicon samples however, exhibit these non linearities. We present a non linear model based on Auger recombination that can explain the observed signal for both intrinsic and implanted samples.
\end{abstract}

\section{INTRODUCTION}

Modulated photoreflectance has become one of the most widely used implantation characterisation tool in semiconductor industry [1]. Recently we have shown, theoretically and experimentally, that the high densities of free carriers injected in such experiments requires to consider Auger recombination, resulting in nonlinear photoreflectance signal [2]. In this paper, we extend our non linear modelisation to the case of recombination in the implanted layer. We will see how the combination of non linear effects leads to a photoreflectance signal which is linear with the pump laser power, opening the way to a explanation of signal dependance as a function a implantation dose.

\section{EXPERIMENTAL PROCEDURE AND RESULTS}

We measured the photoreflectance signal at $500 \mathrm{kHz}$ on two silicon wafers (one intrinsic and one implanted) with a "classical" photothermal microscope [3] using a $\times 5$ objective. The somewhat large beam size $\left(\cong 10 \mu \mathrm{m}^{2}\right)$ and high modulation frequency were used in order to keep to the monodimensionnal diffusion model, as three dimensionnal diffusion can change dramatically the conditions for non linear effects to appear [4]

Figure 2 shows the dependence of the amplitude and of the phase of the signal as a function of the excitation power $(\phi)$. In figure 1 we compare experimental results on intrinsic and implanted Si wafers. The non linearity of the signal appears clearly for the intrinsic sample and has been discussed in [2]. We can note :

amplitude : the variation of the slope, indicating successive dependences in $\phi, \sqrt{\phi}$ and $\phi^{3 / 2}$;

phase: the $180^{\circ}$ shift, indicating that the thermal contribution, which increases faster with pump intensity $\left(\phi^{3 / 2}\right.$ compared to $\left.\sqrt{\phi}\right)$, becomes dominant at high incident powers $(I>0,5 \mathrm{~W})$. 
Implanted silicon samples however, do not exhibit the non linear dependence. Under the same excitation flux, the amplitude of $\Delta R / R$ remains linear as a function of incident power (see figure 1,0 ). Furthermore, the thermal contribution (whose phase is near $0^{\circ}$ ) remains dominant for all powers investigated. This is true for all samples we have studied: Boron and Arsenic implantation with doses ranging from $10^{11}$ to $10^{15} \mathrm{~cm}^{-2}$.

\section{MODELISATION}

Our non linear modelisation is based on non linear recombination processes for free carriers, Auger recombination in particular (see figure 2). Auger recombination is process involving three carriers; the resulting lifetime is inversly proportionnal to the square of the free carrrier density $\tau=1 / \gamma n^{2}$ (where $\gamma$ is the Auger coefficient) [5]. The free carrier diffusion equation is thus written :

$\frac{\partial n}{\partial t}=\nabla^{2} n-n\left(\frac{1}{\tau}+\gamma n^{2}\right) \approx \nabla^{2} n-\gamma n^{3}$

We have shown that solving this equation considering Auger recombination as the dominant recombination process leads to a dependance in $\sqrt{\phi}$ for the plasma contribution and in $\phi^{3 / 2}$ for the heat contribution, in agreement with the experimental observations [2].

\subsection{Case of implanted wafers}

We can expand this modelisation by considering trap assisted Auger recombination in the implanted layer (see figure 2 right). In this case, the energy transferred to a free carrier is that of the recombination through a trap state. Two carriers are involved and the lifetime associated with this process is inversly proportional to free carrier density $n(\tau \propto 1 / n)$. Therefore, the heat generation associated with it is proportional to the square of the free carrier density.

The free carrier density itself being proportionnal to the square root of the incident power, therefore we find that heat generation in the implanted layer is linear with incident power. This change in the dominant recombination process from Auger in intrinsic samples to trap assisted Auger in implanted ones is also coherent with the increase in photoreflectance signal (see figure 1), and is confirmed by
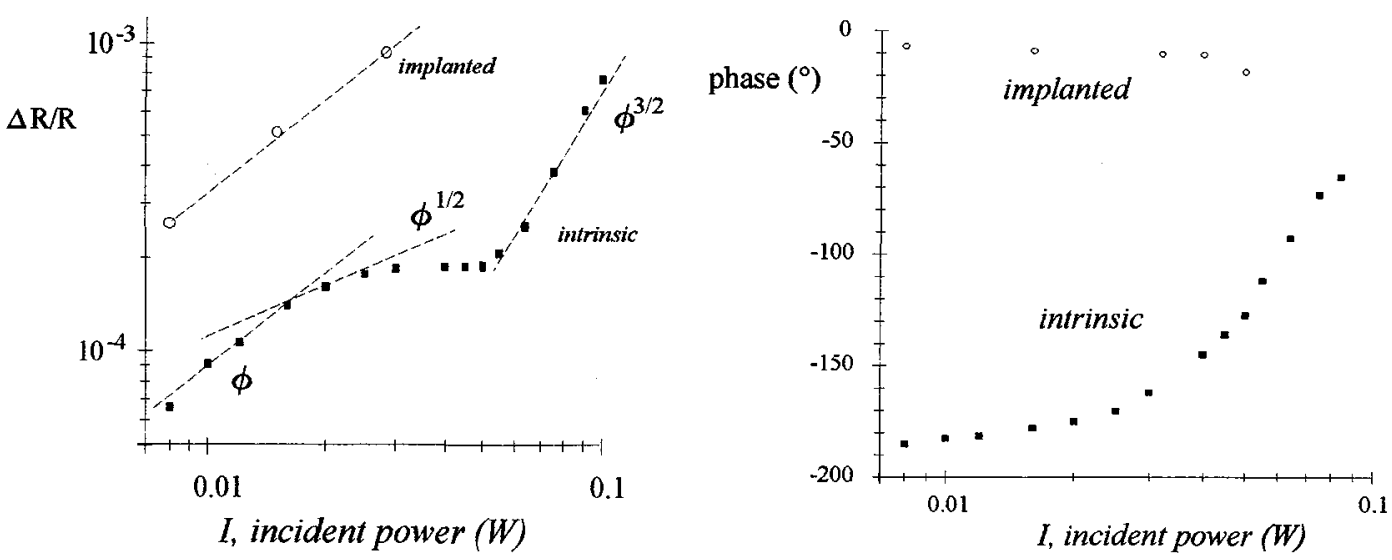

Figure 1. Left: Amplitude of the photoreflexion signal. For intrinsic silicon, the signal exhibits three characteristic slopes, $\mathrm{m}$; (1) linear; (2) nonlinear carrier contribution; (3) nonlinear thermal contribution. For implantd samples the signal remains linear. Right: Phase of the signal. For intrinsic silicon, the $180^{\circ}$ phase shift indicates a change in the dominant contribution from plasma to heat. For implanted samples, the thermal contribution dominates at all powers investigated. 

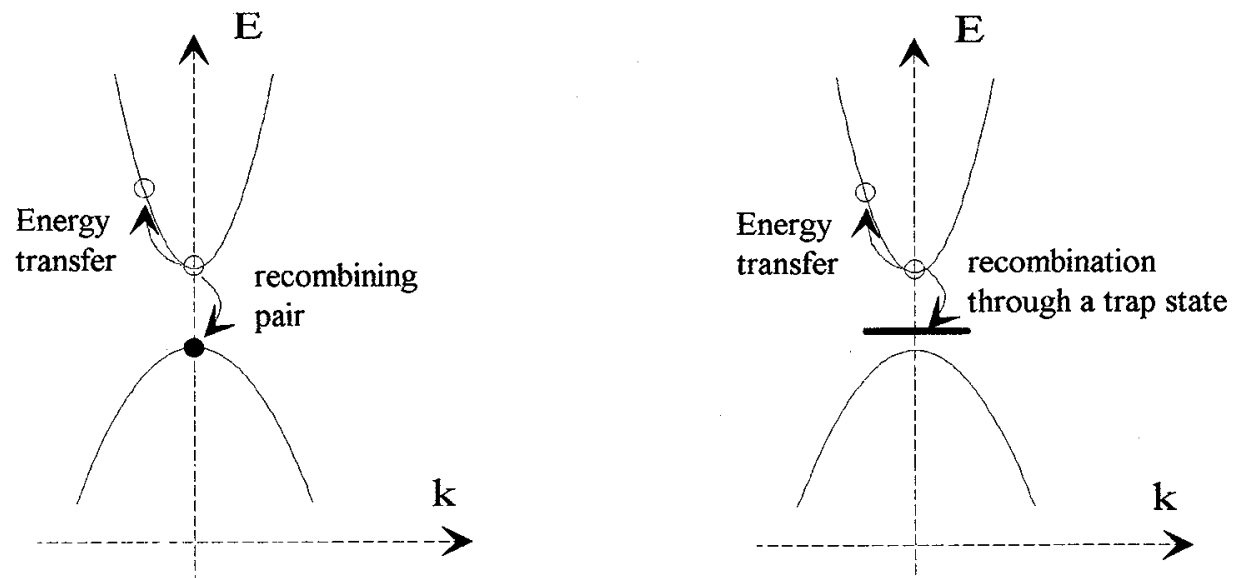

Figure 2: Auger (left) and trap-assisted Auger (right) recombination processes. These processes become important for large free carrier densities. In both cases, the recombination energy is transferred to a free carrier, which will relax the minimum of the band restituting the energy by non radiative processes. For Auger recombination, this energy is that of the band-to-band recombination; for trap-assisted Auger the energy is that of the recombination through a trap state.

transient free carrier gratings experiments [6].

Because the implanted layer is very thin and close to the surface, we will treat its effect as a boundary condition for the heat diffusion equation : we will thus introduce a non linear surface recombination velocity $\beta$ and write the condition as :

$\left.\chi \frac{\partial T}{\partial z}\right|_{z=0}=\left(h \nu-E_{g}\right) \phi+E_{g}(\beta n) n=\left(h \nu-E_{g}\right) \phi+E_{g} \beta n^{2}(0)$

where $\chi$ is the thermal conductivity, Eg the band gap energy and pump beam $h \nu$ the photon energy.

The factor $\beta$ expresses the recombination probability in the implanted layer. This probability being a function of the trap state density, $\beta$ should be the result of the integration of this density over the implanted layer and therefore should be directly proportional to the implantation dose. As a first attempt to model the effect of implantation on photoreflexion signal we will express the factor as : $\beta=c \times \operatorname{Imp}$, where Imp is the implantation dose and $c$ is a constant which should depend on the nature of the implant and the implantation energy.

We have measured the photoreflectance signal on two series of wafers : one implanted with $\mathrm{As}^{+}$at $40 \mathrm{keV}$ and one implanted with $\mathrm{B}^{+}$at $50 \mathrm{keV}$. We have then fitted both set of results by changing only the phenomenological parameter $c$. The agreement is quite good between theory and experimental measure of the amplitude of $\Delta R / R$ as a function of the implantation dose, as well as between the fitted and published values for the properties of $\mathrm{Si}$ (see figure 3 and table 1).

\section{CONCLUSION}

We have expanded the application of photothermal examination of semiconductors by introducing non linear effects. We have shown that linear signal can be in fact the result of two non linear recombination processes and proposed that such non linear processes play a critical role in the case of implantation characterization. These first results are quite encouraging and gives hope for quantitative evaluation of the implantation in this field. In order to do so, a formal relation between the nature and dose of implantation and factor $\beta$ must be established. 


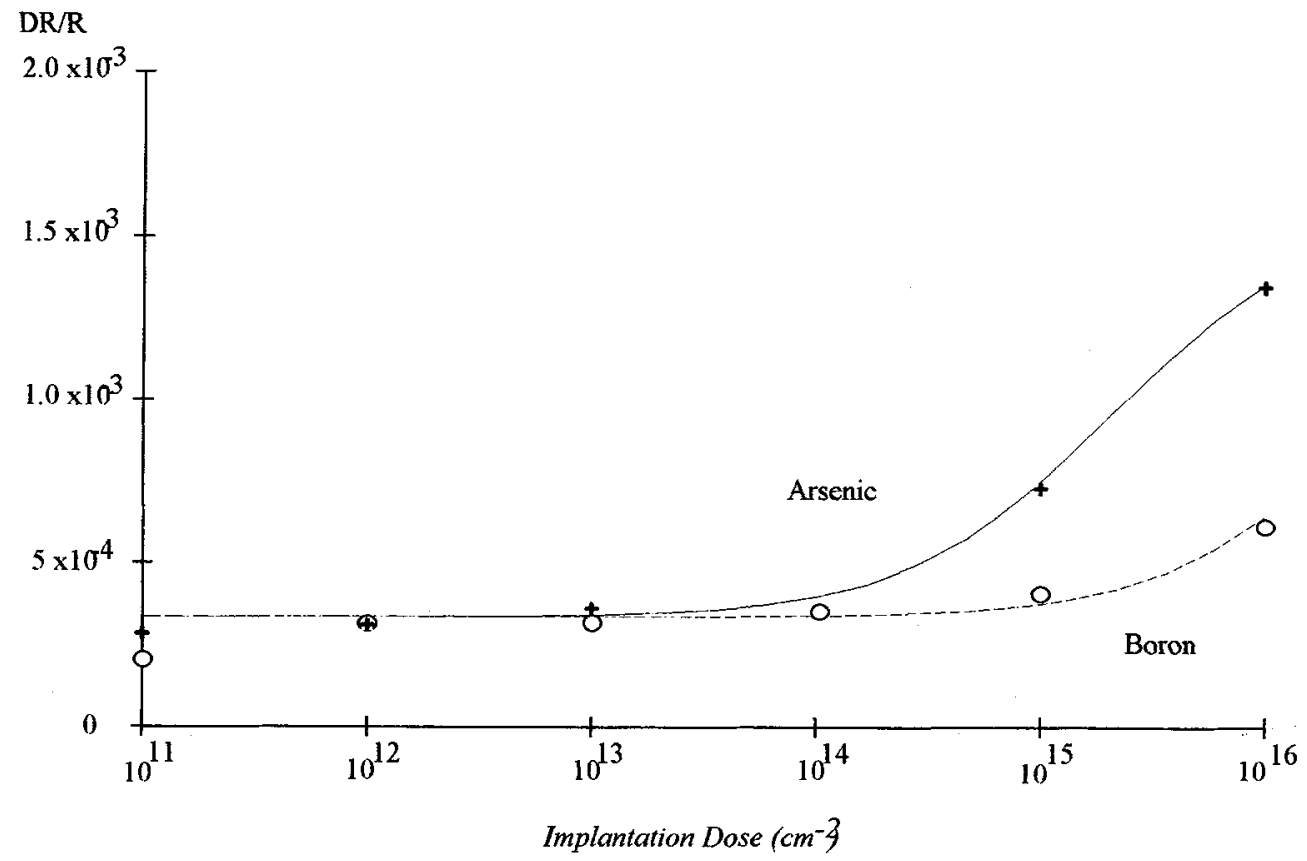

Figure 3 : Experimental and theoretical calculation of the photoreflectance signal as a function of Implantion dose for Boron ans Arsenic implanted Si wafers.

Table 1: Fitted parameters

\begin{tabular}{|c|r|l||r|r|l||}
\hline$D$ & 17 & $\mathrm{~cm}^{2 / s}$ & $\phi$ & $2.29 \times 10^{22}$ & $\mathrm{~s}^{-1} \mathrm{~cm}^{-2}$ \\
\cline { 3 - 5 } & $4 \times 10^{-31}$ & $\mathrm{~cm}^{6} / \mathrm{s}$ & & $8,86 \times 10^{3}$ & $\mathrm{~W} / \mathrm{cm}^{2}$ \\
\hline$C^{\prime}$ for $A s^{+}$ & $1.13 \times 10^{-30}$ & $\mathrm{~cm}^{6} / \mathrm{s}$ & $\chi_{T}$ & 1.5 & $\mathrm{~W} / \mathrm{K} \cdot \mathrm{cm}$ \\
\hline$C$ for $B+$ & $7.4 \times 10^{-32}$ & $\mathrm{~cm}^{6} / \mathrm{s}$ & $\bmod$ freq. & 500 & $\mathrm{kHz}$ \\
\hline
\end{tabular}

\section{References}

[1] C.B. Yarling, W.H. Johnson, W.A. Keenan et L.A. Larson, Sol. State Technol. 34, 57 (1991).

[2] B.C. Forget, D. Fournier and V.E. Gusev, Appl.Phys.Lett. 61 (19), 2341 (1992).

[3] A. Rosencwaig, J. Opsal, W.L. Smith and D.L. Willenborg, Appl. Phys. Lett 46, 1013 (1985).

[4] B.C. Forget, D. Fournier and V.E. Gusev, this conference.

[5] A. Haug, Solid State Comm. 25, 477 (1978).

[6] J. Viatkus, K. Jarasiunas, E. Gaubas, L. Jonkias, R. Pranaitis and L. Subacius, IEEE J. Quantum Electron. QE-22, 1298 (1986). 